\title{
Rancang Bangun Manajemen Bimbingan Tugas Akhir Pada Jurusan Teknik Industri Universitas Muhammadiyah Malang
}

\author{
Aristy Indana Zulfa ${ }^{* 1}$, Wildan Suharso ${ }^{2}$, Shanty Kusuma Dewi ${ }^{3}$ \\ 1,2Teknik Informatika/Universitas Muhammadiyah Malang \\ ${ }^{3}$ Teknik Industri/Universitas Muhammadiyah Malang \\ aristy_437057@webmail.umm.ac.id ${ }^{* 1}$, wsuharso@umm.ac.id ${ }^{2}$, shanty@umm.ac.id ${ }^{3}$
}

\begin{abstract}
Abstrak
Tugas akhir merupakan suatu karya tulis ilmiah, berupa paparan tulisan hasil penelitian yang wajib diselesaikan oleh setiap mahasiswa untuk mendapatkan gelar sarjana. Pada jurusan Teknik Industri terdapat beberapa proses tahapan yang harus dilakukan oleh mahasiswa, diantaranya pendaftaran dosen pembimbing, seminar proposal dan sidang akhir. Sejauh ini pendaftaran yang dilakukan masih menggunakan google form dimana hanya sebatas untuk pendaftaran saja, dan untuk laporan bimbingan tugas akhir belum tercatat dengan baik dan dilakukan secara manual menggunakan lembar asistensi yang ada pada logbook skripsi sehingga dosen pembimbing dan koordinatosr tugas akhir kesulitan dalam memonitoring mahasiswa bimbingannya. Tujuan dari penelitian ini adalah untuk membangun sistem berbasis website dengan menggunakan framework codeigniter dan metode waterfall. Tahapan yang dilalui dalam metode waterfall meliputi analisa kebutuhan, desain sistem, imeplementasi dan pengujian sistem. Hasil pada penelitian ini adalah sistem manajemen bimbingan tugas akhir pada jurusan teknik industri universitas muhammadiyah malang yang dapat memonitoring, membantu pelaporan kegiatan bimbingan, dan pendaftaran pada proses tugas akhir.
\end{abstract}

Kata Kunci: Teknik Industri, Monitoring, Sistem Manajemen, Waterfall

\section{Abstract}

The final assignment is a scientific paper, in the form of writing research results that must be completed by each student to get a bachelor's degree. In the Department of Industrial Engineering there are several stages of the process that must be done by students, including registration of supervisors, seminar proposals and final hearings. So far the registration is still using google form where it is only limited to registration, and for the final assignment guidance report has not been recorded properly and done manually using the assistance sheet in the thesis logbook so the final assignment supervisor and coordinator has difficulty monitoring the student's guidance. The purpose of this study is to build a website-based system using the codeigniter framework and the waterfall method. The stages passed in the waterfall method include needs analysis, system design, implementation and system testing. The results of this research are the final assignment guidance management system in the industrial engineering department of Muhammadiyah Malang University which can monitor, assist in reporting guidance activities, and registration in the final assignment process.

Keywords: Industrial Engineering, Monitoring, Management System, Waterfall

\section{Pendahuluan}

Semakin berkembangnya teknologi informasi, khususnya internet memungkinkan pengembangan layanan informasi yang lebih baik dalam institusi pendidikan. Teknologi informasi merupakan teknologi yang berfungsi untuk mengelola suatu data, mulai dari memproses, mendapatkan, menyusun, menyimpan hingga mengubah sebuah data dalam berbagai macam cara untuk memperoleh hasil informasi yang berkualitas, yaitu informasi yang sesuai, akurat dan tepat waktu, yang mana berguna untuk keperluan pribadi, akademisi, bisnis dan pemerintahan. Selain itu teknologi informasi termasuk informasi yang stategis dalam mengambil keputusan [1]. Ada banyak lingkup tata kelola yang ada didalam perguruan tinggi. Pemanfaatan dari teknologi informasi dan komunikasi di layanan administrasi akademik menjadi sebuah kebutuhan agar menghasilkan pelayanan informasi yang baik dan mudah diakses [2]. 
Sistem informasi adalah sebuah kumpulan dari beberapa elemen atau komponen yang saling terhubung satu sama lain, yang mana dapat memproses data seperti, mengolah, menyimpan dan menginputkan serta menghasilkan data dan informasi, selain itu juga dapat memberikan timbal balik agar tercapainya suatu tujuan organisasi [3]. Peran dari sistem informasi salah satunya, untuk mengendalikan dan mengatur aktivitas-aktivitas dari erbagai macam sub sistem dalam organisasi sehingga tujuan dari organisasi tersebut tercapai [4].

Pemanfaatan sistem informasi dan teknologi informasi yang tepat dan benar dapat digunakan sebagai salah satu senjata strategis dan senjata kompetitif dalam memberikan sebuah nilai lebih yaitu, competitive advantage dalam alur bisnis Perguruan Tinggi [5]. Di perguruan tinggi untuk mendapatkan gelar sarjana setiap mahasiswa diwajibkan untuk membuat sebuah tugas akhir skripsi. Tugas Akhir/ Skripsi merupakan suatu karya tulis ilmiah, berupa paparan tulisan hasil penelitian yang membahas suatu masalah dengan menggunakan kaidah-kaidah ilmiah yang berlaku.

Saat ini Universitas Muhammadiyah Malang telah banyak melakukan pengembangan sistem informasi dalam bidang akademika. Namun tidak sedikit pula yang masih menggunakan sistem seadanya. Di jurusan teknik industri sebelumnya telah dilakukan pendaftaran tugas akhir melalui website teknik industri, yang mana masih terbatas menggunakan google form.

Jurusan Teknik Industri adalah salah satu program studi di Fakultas Teknik Universitas Muhammadiyah Malang. Berperan dalam penyelenggaraan bidang perancangan, penginstalan, dan perbaikan sistem integral dan berkontribusi bagi pengembangan ilmu pengetahuan dan teknologi dalam bidang Teknik Industri di Universitas Muhammadiyah Malang.

Proses tahapan untuk alur pendaftaran tugas akhir di jurusan teknik industri terdiri dari pengajuan judul, pengajuan dosen pembimbing, penerbitan SK TA, proses bimbingan, pendaftaran seminar proposal, pelaksanaan seminar proposal, pendaftaran sidang skripsi, pelaksanaan sidang skripsi, dan berakhir pada pelaksanaan ujian seminar hasil. Dalam proses tersebut, mahasiswa hanya dapat melakukan sebatas pendaftaran melalui website teknik industri yang akan direkap secara berkala oleh koordinator TA. Selain itu masalah utama dihadapi adalah, pada pelaksanaan untuk menyelesaikan tugas akhir proses bimbingan tidak tercatat dengan baik. Mahasiswa diharuskan melakukan bimbingan, namun pada kenyataannya intensitas bimbingan dan komunikasi dengan dosen pembimbing tidak selalu lancar. Banyaknya mahasiswa yang masa bimbingannya sudah melebihi (Surat Keputusan Tugas Akhir) SK TA Bimbingan, adanya mahasiswa yang tidak melakukan bimbingan, dan lamanya waktu pengerjaan tugas akhir yang tidak tercatat dengan baik sehingga dosen pembimbing kesulitan untuk memonitoring mahasiswa. Masalah internal maupun eksternal yang terjadi tersebut menjadi faktor banyaknya mahasiswa yang lulus tidak tepat waktu.

Dari penjelasan uraian permasalahan tersebut, maka pada penelitian ini akan dibuat sebuah sistem manajemen menggunakan metode pengembangan sistem model waterfall untuk merancang dan membangun sistem manajemen bimbingan tugas akhir. Model pengembangan SDLC waterfall bisa digunakan untuk sistem perangkat lunak yang bersifat generik, artinya sistem atau perangkat lunak tersebut dapat dianalisa semua kebutuhannya dari awal dengan jenis spesifikasi yang umum dan juga cocok tugas akhir/skripsi yang tujuannya untuk membangun dari awal sebuah sistem dengan mengumpulkan kebutuhan sistem yang diperlukan sesuai topik penelitian yang dipilih sampai dengan pengujian dari produk tersebut [6]. Metode waterfall ini dipilih karena metode ini memungkinkan untuk memudahkan kontrol dan pembagian aktifitas yang berurutan dan berkelanjutan sehingga dapat memperkecil kemungkinan akan terjadinya kesalahan [7].

Pada penelitian sebelumnya tentang sistem informasi bimbingan tugas akhir pada fakultas ilmu komputer dan teknologi informasi universitas mulawarman menggunakan metode waterfall pada pengembangan sistem yang dibuat [8]. Kemudian pada perancangan sistem monitoring skripsi. Pada jurnal penelitian ini menggunakan metode waterfall, yang dirancang untuk dua kategori pengguna yaitu mahasiswa dan dosen [9]. Dan pada sistem informasi manajemen tugas akhir berbasis web jurusan teknik sipil fakultas teknik Universitas Tanjungpura ini menggunakan perancangan sistem untuk memudahkan proses penyelesaian tugas akhir untuk dosen, mahasiswa dan staf yang membutuhkan informasi terkait tugas akhir [10].

Sistem Manajemen Bimbingan Tugas Akhir (SIMTA) memudahkan dalam penyimpanan dan pengolahan data kedalam database menggunakan MySQL serta dapat diakses melalui komputer dan perangkat lainnya yang tersambung ke jaringan internet. SIMTA dibuat berbasis web sehingga dapat diakses oleh mahasiswa baik untuk mendaftar dan dosen pada proses

REPOSITOR, Vol. 2, No. 3, Maret 2020: 321-330 
monitoring bimbingan tugas akhir, serta koordinator TA untuk mendapatkan rekapan informasi meliputi tugas akhir yang dibutuhakan.

Dengan pengembangan sistem manajemen bimbingan tugas akhir ini, diharapkan akan dapat menyelesaikan permasalahan yang ada, sehingga dapat memberikan dampak positif, memudahkan serta dapat meningkatkan kinerja terhadap proses bimbingan tugas akhir baik itu dosen maupun mahasiswa untuk lulus tepat waktu, guna mewujudkan kualitas sistem pendidikan yang tinggi di jurusan Teknik Industri Universitas Muhammadiyah Malang.

\section{Metode Penelitian}

\subsection{Model Pengembangan Sistem}

Pada tahapan penyelesaian masalah dalam pembuatan tugas akhir ini mengunakan beberapa tahapan, diantaranya digambarkan dalam bentuk Gambar 1 berikut.

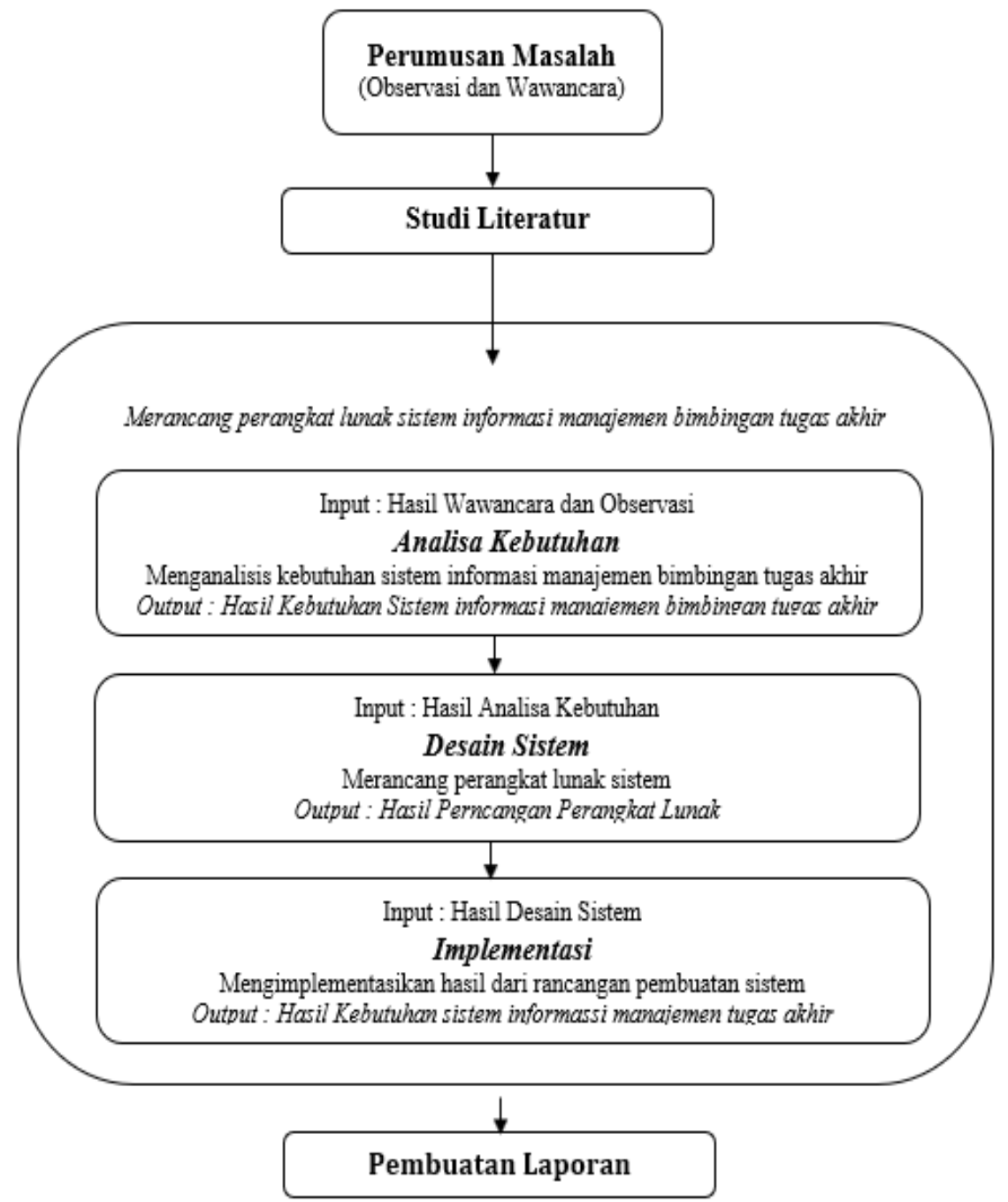

Gambar 1. Tahapan Pengembangan Sistem

\subsubsection{Studi Literatur}

Pada pengembangan sistem informasi manajemen bimbingan tugas akhir ini dilakukan perancangan desain sistem menggunakan tahapan Software Developmen Lifecycle dengan model pengembangan Waterfall sehingga memungkinkan adanya perbaikan sistem pada tahap tertentu tanpa harus menyelesaikan seluruh tahapan pengembangan sistem. Dalam pengembangannya waterfall memiliki beberapa tahapan diantaranya digambarkan pada Gambar 2 berikut. 


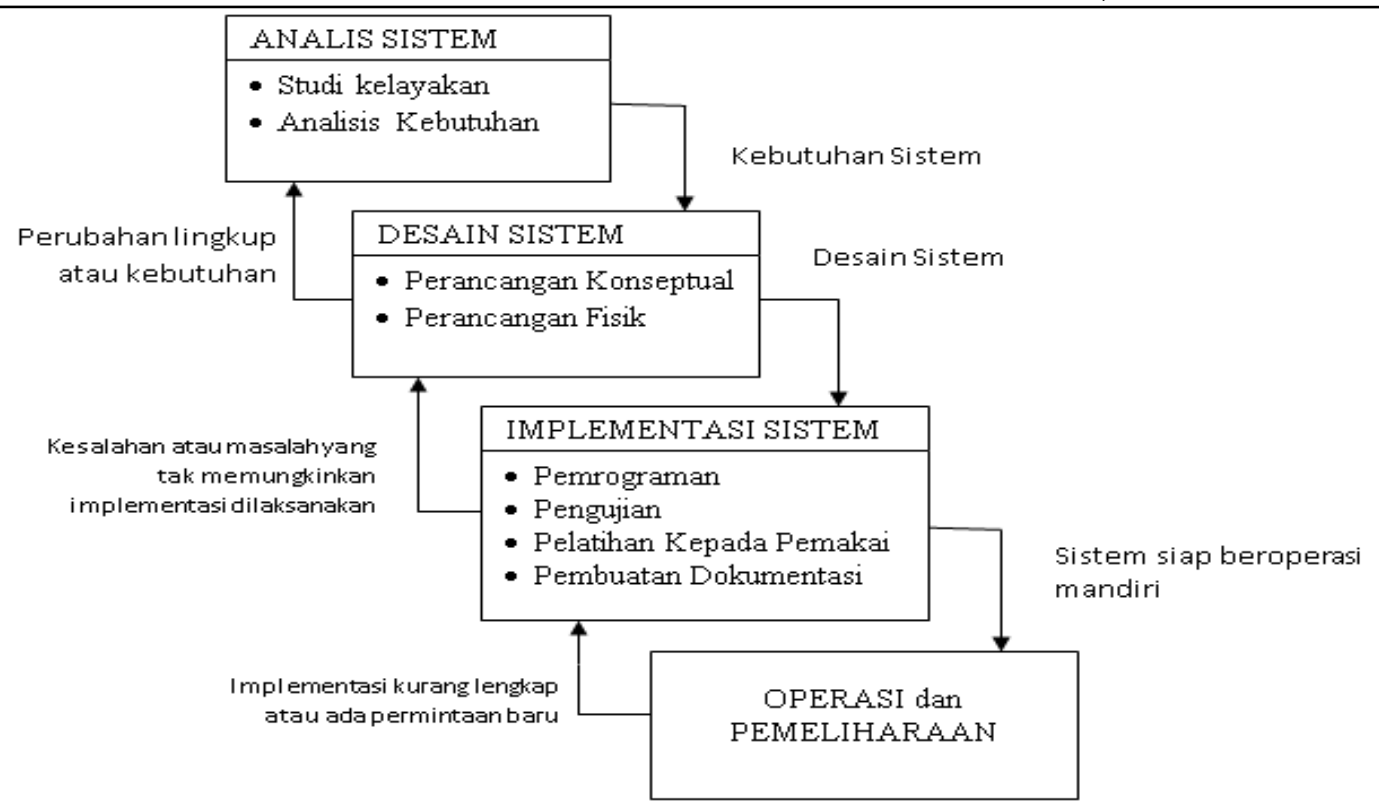

Gambar 2. Pengembangan Perangkat Lunak Model SDLC -Waterfall

Pada Gambar 2 digambarkan tahapan pengembangan perangkat lunak yang digunakan pada sistem. Namun di tahapan operasi dan pemeliharaan tidak dilakukan, dan berhenti pada tahap implementasi. Hal ini dilakukan karna pengembangan ini hanya bertujuan untuk menghasilkan sistem saja, dimana untuk operasi dan pemeliharaan sistem akan dilakukan oleh pihak Jurusan Teknik Industri Universitas Muhammadiyah Malang.

\section{a. Analisis Sistem}

Menganalisa data yang telah diperoleh untuk mengembangkan sistem yang ada dengan tujuan memperoleh hasil yang lebih baik. Pengumpulan kebutuhan dilakukan secara intensif untuk menspesifikasikan kebutuhan perangkat lunak agar dapat dipahami perangkat lunak agar dapat dipahami perangkat lunak apa yang dibutuhkan oleh user.

\section{b. Perancangan Desain}

Proses desain sistem dan menerjemahkan kebutuhan kesebuah perancangan perangkat lunak yang dapat diperkirakan sebelum masuk ke tahap implementasi.

\section{c. Implemetasi}

Mengimplementasikan seluruh kebutuhan sistem yang harus dilakukan mulai dari awal kegiatan hingga akhir pada sistem yang akan dibangun.

\subsection{Analisa Kebutuhan}

Penggalian informasi mengenai fungsi serta kebutuhan sistem dengan cara melakukan tinjauan secara langsung serta melakukan wawancara kepada beberapa sumber yaitu mahasiswa semester akhir, dosen pembimbing, koordinator tugas akhir, staff tu dari jurusan Teknik Industri UMM serta data yang diambil dari website www.industri.umm.ac.id, mengenai alur pendaftaran dan bimbingan tugas akhir yang ada di jurusan teknik industri Universitas Muhammadiyah Malang.

\subsubsection{Kebutuhan Pengguna}

Pada pengembangan Sistem Manajemen Bimbingan Tugas Akhir ini kebutuhan pengguna hanya berfokus pada 3 pengguna yang dimana setiap pengguna akan saling terhubung dengan pengguna yang lain. Sistem Manajemen bimbingan tugas akhir ini berdasarkan kebutuhan pengguna dibagi menjadi 3, yaitu Koordinator TA, Dosen Pembimbing, dan Mahasiswa. Setiap pengguna dapat melakukan tugasnya sesuai kebutuhan pengguna yang dideskripsikan. Kedudukan tertinggi adalah Koordinator TA sebagai administrator yang dapat mengelola Informasi Tugas Akhir, Pendaftaran Dosen Pembimbing, SK TA, Pendaftaran Sempro

REPOSITOR, Vol. 2, No. 3, Maret 2020: 321-330 
dan Pendaftaran Sidang Skripsi. Kemudian diikuti oleh Dosen Pembimbing untuk monitoring data bimbingan mahasiswa dan Mahasiswa melakukan pendaftaran Dosen Pembimbing input laporan bimbingan, ujian Seminar Proposal dan ujian Sidang Akhir.

\subsection{Desain Sistem}

Pada pengembangan Sistem Dosen Berprestasi ini terdapat 3 aktor. 3 aktor yang diantaranya Koordinator TA yang menjadi Administrator, Dosen Pembimbing untuk memonitoring pada mahasiswa bimbingannya, dan Mahasiswa sebagai pengguna untuk melakukan pengelolaan data yang berkaitan dengan tugas akhir.

\subsubsection{Arsitektur Sistem}

Pengembangan Sistem infromasi manajemen bimbingan tugas akhir pada jurusan teknik industri ini berdasarkan penjelasan pada kebutuhan fungsional merupakan gabungan dari software, hardware dan user. Berikut ini gambaran arsitektur dari implementasi pengembangan sistem yang akan diterapkan.

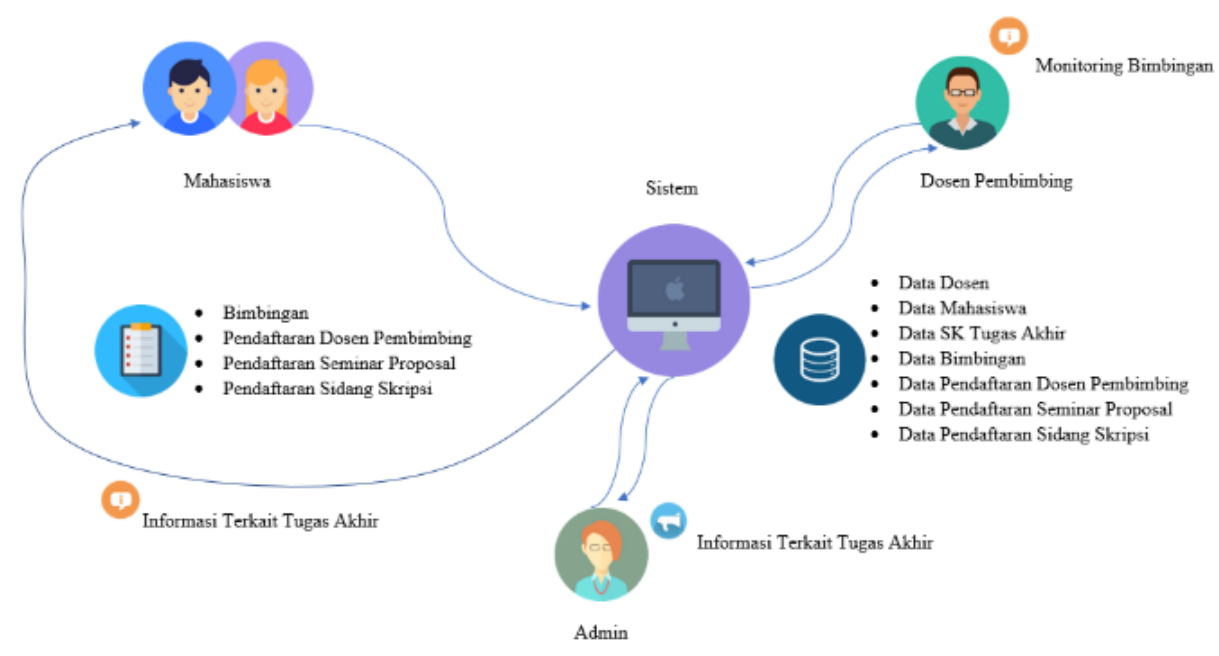

Gambar 3. Arsitektur Sistem Manajemen Bimbingan Tugas Akhir

Pada Gambar 3 digambarkan bahwa arsitektur pada sistem informasi manajemen bimbingan tugas akhir ini adalah gabungan dan pengembangan dari alur yang sudah ada, yang mana pada sistem ini dibuat menggunakan database yang memadai, sehingga nantinya akan lebih memudahlan user dalam pemanfaatan dan penggunaannya.

\section{Implementasi}

\subsection{Implementasi Sistem}

Implementasi sistem dilakukan setelah menganalisis seluruh kebutuhan yang dibutuhkan oleh sistem. Pada tahap ini akan dijelaskan tentang hasil implementasi sistem manajemen bimbingan tugas akhir. Berikut adalah screen shoot hasil dari implementasi sistem:

\section{Home}

Halaman ini adalah tampilan pada saat pertama kali mengakses SIM TA Teknik Industri. Terdapat menu Home dan menu Login di sebelah pojok kanan atas. Menu home akan menampilkan halaman ini dan menu login akan menampilkan laman login.

\section{Login}

Pada halaman ini ketika user memilih menu login pada halaman home sebelumnya, akan ditampilkan form login user. User harus menginputkan username dan password.

\section{Dashboard Admin}

Halaman ini adalah tampilan pada Dashboard Admin, yang terdiri dari beberapa menu diantaranya: informasi, sk bimbingan, dosen, mahasiswa, bimbingan, pendaftaran dospem, pendaftaran sempro dan pendaftaran sidang. 


\section{Bimbingan Dosen}

Halaman ini adalah laman Bimbingan Dosen, dimana dosen dapat melihat record data bimbingan yang telah diinputkan oleh mahasiswa bimbingannya setelah melakukan bimbingan.

\section{Bimbingan Mahasiswa}

Halaman ini adalah laman Bimbingan Mahasiswa, dimana mahasiswa dapat menyimpan record, menambahkan dan menghapus data bimbingan yang diinputkan oleh mahasiswa setelah melakukan bimbingan pada masing-masing dosen.

\section{Daftar Dospem Mahasiswa}

Halaman ini adalah laman Daftar Dospem pada user mahasiswa, dimana mahasiswa dapat mendaftarkan dirinya untuk pengajuan dosen pembimbing.

\section{Daftar Sempro Mahasiswa}

Halaman ini adalah laman Daftar Sempro pada user mahasiswa, dimana mahasiswa dapat mendaftarkan dirinya untuk mengikuti ujian seminar proposal.

\section{Daftar Sidang Mahasiswa}

Halaman ini adalah laman Daftar Sidang pada user mahasiswa, dimana mahasiswa dapat mendaftarkan dirinya untuk mengikuti ujian sidang akhir skripsi.

\section{Sign Out}

Halaman ini adalah laman Sign Out, dimana user dapat keluar dari sistem dengan memilih tombol user (admin/dosen/mahasiswa) yang ada pada pojok kanan atas kemudian pilih tombol keluar.

\subsection{Pengujian}

Pengujian dilakukan untuk mengetahui bahwa sistem yang dibuat bekerja dengan baik dan sistem sudah sesuai dengan tujuan dari penelitian. Pengujian yang ditunjukkan pada Tabel 1, dilakukan pada sistem manajemen bimbingan tugas akhir ini menggunakan pengujian Black-box.

Tabel 1. Pengujian Blackbox

\begin{tabular}{|c|c|c|c|c|c|}
\hline No & User & $\begin{array}{l}\text { Deskripsi } \\
\text { pengujian }\end{array}$ & Prosedur pengujian & Sesuai & $\begin{array}{l}\text { Tidak } \\
\text { Sesuai }\end{array}$ \\
\hline \multirow{14}{*}{1.} & \multirow{14}{*}{ Admin } & Home & $\begin{array}{l}\text { Menampilkan halaman } \\
\text { home website }\end{array}$ & $\sqrt{ }$ & \\
\hline & & Login & $\begin{array}{c}\text { Memasukkan username } \\
\text { dan password }\end{array}$ & $\sqrt{ }$ & \\
\hline & & & $\begin{array}{c}\text { Masuk kedalam halaman } \\
\text { admin }\end{array}$ & $\sqrt{ }$ & \\
\hline & & Dashboard & Klik dashboard & $\sqrt{ }$ & \\
\hline & & & $\begin{array}{c}\text { Menampilkan halaman } \\
\text { dashboard admin }\end{array}$ & $\sqrt{ }$ & \\
\hline & & Informasi & Klik informasi & $\sqrt{ }$ & \\
\hline & & & $\begin{array}{l}\text { Menampilkan halaman } \\
\text { informasi }\end{array}$ & $\sqrt{ }$ & \\
\hline & & & Menambah data informasi & $\sqrt{ }$ & \\
\hline & & & Menghapus data informasi & $\sqrt{ }$ & \\
\hline & & Sk bimbingan & Klik sk bimbingan & $\sqrt{ }$ & \\
\hline & & & $\begin{array}{c}\text { Menampilkan sk } \\
\text { bimbingan }\end{array}$ & $\sqrt{ }$ & \\
\hline & & & $\begin{array}{c}\text { Menambahkan data sk } \\
\text { bimbingan }\end{array}$ & $\sqrt{ }$ & \\
\hline & & & $\begin{array}{l}\text { Menghapus data sk } \\
\text { bimbingan }\end{array}$ & $\sqrt{ }$ & \\
\hline & & & $\begin{array}{c}\text { Mendownload data sk } \\
\text { bimbingan }\end{array}$ & & \\
\hline
\end{tabular}

REPOSITOR, Vol. 2, No. 3, Maret 2020: 321-330 


\begin{tabular}{|c|c|c|c|c|}
\hline & $\begin{array}{l}\text { Pendaftaran } \\
\text { dospem }\end{array}$ & Klik pendaftaran dospem & $\sqrt{ }$ \\
\hline & & & $\begin{array}{l}\text { Menampilkan pendaftaran } \\
\text { dospem }\end{array}$ & $\sqrt{ }$ \\
\hline & & & $\begin{array}{c}\text { Mendownload pendaftaran } \\
\text { dospem }\end{array}$ & $\sqrt{ }$ \\
\hline & & $\begin{array}{l}\text { Pendaftaran } \\
\text { sempro }\end{array}$ & Klik pendaftaran sempro & $\sqrt{ }$ \\
\hline & & & $\begin{array}{c}\text { Menampilkan pendaftaran } \\
\text { sempro }\end{array}$ & $\sqrt{ }$ \\
\hline & & & $\begin{array}{l}\text { Mendownload pendaftaran } \\
\text { sempro }\end{array}$ & $\sqrt{ }$ \\
\hline & & $\begin{array}{l}\text { Pendaftaran } \\
\text { sidang }\end{array}$ & Klik pendaftaran sidang & $\sqrt{ }$ \\
\hline & & & $\begin{array}{l}\text { Menampilkan pendaftaran } \\
\text { sidang }\end{array}$ & $\sqrt{ }$ \\
\hline & & & $\begin{array}{l}\text { Mendownload pendaftaran } \\
\text { sidang }\end{array}$ & $\sqrt{ }$ \\
\hline & & Sign out & Klik keluar & $\sqrt{ }$ \\
\hline & & & $\begin{array}{l}\text { Menampilkan halaman } \\
\text { login }\end{array}$ & $\sqrt{ }$ \\
\hline \multirow{14}{*}{2.} & \multirow{14}{*}{ Dosen } & Home & $\begin{array}{c}\text { Menampilkan halaman } \\
\text { home website }\end{array}$ & $\sqrt{ }$ \\
\hline & & Login & $\begin{array}{c}\text { Memasukkan username } \\
\text { dan password }\end{array}$ & $\sqrt{ }$ \\
\hline & & & $\begin{array}{c}\text { Masuk kedalam halaman } \\
\text { dosen }\end{array}$ & $\sqrt{ }$ \\
\hline & & Profile & Klik profile & $\sqrt{ }$ \\
\hline & & & $\begin{array}{l}\text { Menampilkan halaman } \\
\text { profile dosen }\end{array}$ & $\sqrt{ }$ \\
\hline & & & Mengedit data profile & $\sqrt{ }$ \\
\hline & & Bimbingan & Klik bimbingan & $\sqrt{ }$ \\
\hline & & & $\begin{array}{c}\text { Menampilkan halaman } \\
\text { bimbingan }\end{array}$ & $\sqrt{ }$ \\
\hline & & & $\begin{array}{c}\text { Menambah data saran } \\
\text { bimbingan }\end{array}$ & $\sqrt{ }$ \\
\hline & & & $\begin{array}{c}\text { Menghapus data } \\
\text { bimbingan }\end{array}$ & $\sqrt{ }$ \\
\hline & & Sk bimbingan & Klik sk bimbingan & $\sqrt{ }$ \\
\hline & & & $\begin{array}{c}\text { Menampilkan sk } \\
\text { bimbingan }\end{array}$ & $\sqrt{ }$ \\
\hline & & Sign out & Klik keluar & $\sqrt{ }$ \\
\hline & & & $\begin{array}{l}\text { Menampilkan halaman } \\
\text { login }\end{array}$ & $\sqrt{ }$ \\
\hline \multirow{6}{*}{3} & \multirow{6}{*}{ Mahasiswa } & Home & $\begin{array}{c}\text { Menampilkan halaman } \\
\text { home website }\end{array}$ & $\sqrt{ }$ \\
\hline & & Login & $\begin{array}{l}\text { Memasukkan username } \\
\text { dan password }\end{array}$ & $\sqrt{ }$ \\
\hline & & & $\begin{array}{c}\text { Masuk kedalam halaman } \\
\text { mahasiswa }\end{array}$ & $\sqrt{ }$ \\
\hline & & Informasi & Klik informasi & $\sqrt{ }$ \\
\hline & & & $\begin{array}{c}\text { Menampilkan halaman } \\
\text { informasi }\end{array}$ & $\sqrt{ }$ \\
\hline & & Bimbingan & $\begin{array}{c}\text { Menampilkan halaman } \\
\text { bimbingan }\end{array}$ & $\sqrt{ }$ \\
\hline
\end{tabular}




\begin{tabular}{|c|c|c|}
\hline & $\begin{array}{l}\text { Menambahkan data } \\
\text { bimbingan }\end{array}$ & $\sqrt{ }$ \\
\hline & $\begin{array}{l}\text { Menghapus data } \\
\text { bimbingan }\end{array}$ & $\sqrt{ }$ \\
\hline \multirow[t]{5}{*}{$\begin{array}{c}\text { Pendaftaran } \\
\text { dospem }\end{array}$} & Klik pendaftaran dospem & $\sqrt{ }$ \\
\hline & $\begin{array}{c}\text { Menampilkan pendaftaran } \\
\text { dospem }\end{array}$ & $\sqrt{ }$ \\
\hline & Klik tombol daftar & $\sqrt{ }$ \\
\hline & $\begin{array}{l}\text { Mengisikan form data } \\
\text { pendaftaran }\end{array}$ & $\sqrt{ }$ \\
\hline & $\begin{array}{l}\text { Menampilkan form } \\
\text { konfirmasi pendaftaran }\end{array}$ & $\sqrt{ }$ \\
\hline \multirow[t]{5}{*}{$\begin{array}{l}\text { Pendaftaran } \\
\text { sempro }\end{array}$} & Klik pendaftaran sempro & $\sqrt{ }$ \\
\hline & $\begin{array}{c}\text { Menampilkan pendaftaran } \\
\text { sempro }\end{array}$ & $\sqrt{ }$ \\
\hline & Klik tombol daftar & $\sqrt{ }$ \\
\hline & $\begin{array}{l}\text { Mengisikan form data } \\
\text { pendaftaran }\end{array}$ & $\sqrt{ }$ \\
\hline & $\begin{array}{c}\text { Menampilkan form } \\
\text { konfirmasi pendaftaran }\end{array}$ & $\sqrt{ }$ \\
\hline \multirow[t]{5}{*}{$\begin{array}{l}\text { Pendaftaran } \\
\text { sidang }\end{array}$} & Klik pendaftaran sidang & $\sqrt{ }$ \\
\hline & $\begin{array}{c}\text { Menampilkan pendaftaran } \\
\text { sidang }\end{array}$ & $\sqrt{ }$ \\
\hline & Klik tombol daftar & $\sqrt{ }$ \\
\hline & $\begin{array}{l}\text { Mengisikan form data } \\
\text { pendaftaran }\end{array}$ & $\sqrt{ }$ \\
\hline & $\begin{array}{l}\text { Menampilkan form } \\
\text { konfirmasi pendaftaran }\end{array}$ & $\sqrt{ }$ \\
\hline Sign out & Klik sign out & $\sqrt{ }$ \\
\hline & $\begin{array}{c}\text { Menampilkan halaman } \\
\text { login }\end{array}$ & $\sqrt{ }$ \\
\hline
\end{tabular}

Berdasarkan hasil pengujian yang dilakukan dapat disimpulkan bahwa sistem pada menu admin, dosen dan mahasiswa berfungsi dengan baik dan secara fungsional mengeluarkan hasil yang telah sesuai dengan harapkan.

\section{Kesimpulan}

1. Dari hasil penelitian yang dilakukan menghasilkan sebuah Sistem Manajemen Bimbingan Tugas Akhir pada Jurusan Teknik Industri Universitas Muhammadiyah Malang dengan menggunakan metode waterfall.

2. Dari pengujian yang telah dilakukan dengan menggunakan User Acceptance Test (UAT) sistem ini dapat digunakan secara efektif untuk manajemen bimbingan tugas akhir, membantu untuk monitoring perkembangan bimbingan tugas akhir tiap mahasiswa, membantu mahasiswa dalam pelaporan kegiatan bimbingan tugas akhir, serta membantu mahasiswa dalam pendaftaran proses tugas akhir.

\section{Referensi}

[1] M. Benih And T. Pendidikan, "Diarsipkan Oleh Pls Um Untuk Imadiklus.Com," 2005.

[2] O. E. Indrayani, D. Ipdn, S. Mahasiswa, And A. Upi, "Pengelolaan Sistem Informasi Akademik Perguruan Tinggi Berbasis Teknologi Informasi Dan Komunikasi (Tik," Vol. 12, No. 1, Pp. 45-60, 2011.

[3] G. W. Reynolds, "Ninth Principles Of Information Systems A Managerial Approach Professor Emeritus , Florida State University." 
[4] A. Lipursari, "Peran Sistem Informasi Manajemen (Sim) Dalam Pengambilan Keputusan," Vol. 5, No. 1, Pp. 26-37, 2013.

[5] M. Suyanto, H. Al Fatta, And M. T. Informatika, "Penerapan Information Engineering Untuk Meningkatkan Keunggulan Kompetitif Amikom,” Vol. 11, No. 1, Pp. 104-119, 2018.

[6] R. Susanto, A. D. Andriana, R. Susanto, And A. D. Andriana, "Perbandingan Model Waterfall Dan Prototyping," Vol. 14, No. 1, Pp. 41-46, 2016.

[7] R. S. Pressman, Software Engineering. .

[8] A. Sari, "Sistem Informasi Bimbingan Tugas Akhir Pada Fakultas IImu Komputer Dan Teknologi Informasi Universitas Mulawarman," Vol. 2, No. 1, 2017.

[9] M. R. Ramadhan, L. E. Nugroho, S. Sulistyo, J. Grafika, N. Yogyakarta, And B. Sumur, "Perancangan Sistem Informasi Monitoring Skripsi," Pp. 290-295, 2017.

[10] E. Wulansari, "Perancangan Sistem Informasi Manajemen Tugas Akhir Berbasis Web Jurusan Teknik Sipil Fakultas Teknik Universitas Tanjungpura." 
REPOSITOR, Vol. 2, No. 3, Maret 2020: 321-330 